\title{
Mesothelioma: Live to fight another day
}

\author{
Andrea S. Wolf, MD, MPH, and Raja M. Flores, MD
}

\footnotetext{
From the Department of Thoracic Surgery, Icahn School of Medicine at Mount Sinai, Mount Sinai Health System, New York, NY.

Disclosures: Authors have nothing to disclose with regard to commercial support.

Received for publication Nov 14, 2017; accepted for publication Nov 15, 2017; available ahead of print Jan 13 , 2018.

Address for reprints: Raja M. Flores, MD, Ames Professor of Cardiothoracic Surgery Chairman, Department of Thoracic Surgery, Mount Sinai Health System, Icahn School of Medicine at Mount Sinai, One Gustave L. Levy Place, Box 1023, New York, NY 10029 (E-mail: raja.flores@mountsinai.org).

J Thorac Cardiovasc Surg 2018;155:1855-6 0022-5223/\$36.00

Copyright (C) 2017 by The American Association for Thoracic Surgery https://doi.org/10.1016/j.jtcvs.2017.11.060
}

Ambrogi and colleagues ${ }^{1}$ present another retrospective, single-center, 10-year experience with pleurectomy/decortication (P/D) followed by heated intraoperative chemotherapy (HIOC) for the treatment of malignant pleural mesothelioma (MPM). The study's strengths are inclusion of a full cohort (not only patients with favorable features), comprehensive data, and long-term follow-up (median $>5$ years). The authors should be commended for recognizing that margins are always positive in macroscopic complete resection of MPM, systematizing their intraoperative protocol, minimizing mortality/morbidity, and assuring that all patients received adjuvant therapy.

As in many retrospective cohort studies, weaknesses are largely due to small size. Attempts at multivariable regression yield hazards ratios with little clinical relevance (eg, a hazard ratio of 1.007) and/or confidence intervals with little reliability (eg, 95\% confidence interval of 0.120-0.968), suggesting overfitting of models with too many predictors and too few events. The HIOC protocol is unusual, using a lower dose of cisplatin $\left(80 \mathrm{mg} / \mathrm{m}^{2}\right)$ than what demonstrated more efficacy in cisplatin-only regimens $^{2}$ and a choice of a double agent (epirubicin) that has not been investigated in prospective trials for HIOC in MPM.

The study confirms increasing consensus that lung preservation, ie, P/D or extended P/D (EPD), is paramount in MPM. ${ }^{3}$ Older studies excluded patients who died perioperatively ${ }^{4}$ or evaluated only patients with favorable prognostic features, ${ }^{5}$ circumventing intention-to-treat analysis, limiting the generalizability of results, and overestimating the benefit of extrapleural pneumonectomy (EPP). More recent studies have demonstrated similar overall survival for either procedure but lower operative, short-term, and 1-year mortality with P/D compared with EPP. ${ }^{6-8}$ The group of Ambrogi and colleagues ${ }^{1}$ takes it one step further and advocates leaving the pericardium and diaphragm intact in all cases. Others have shown no difference in survival between P/D and EPD but were biased by tumor

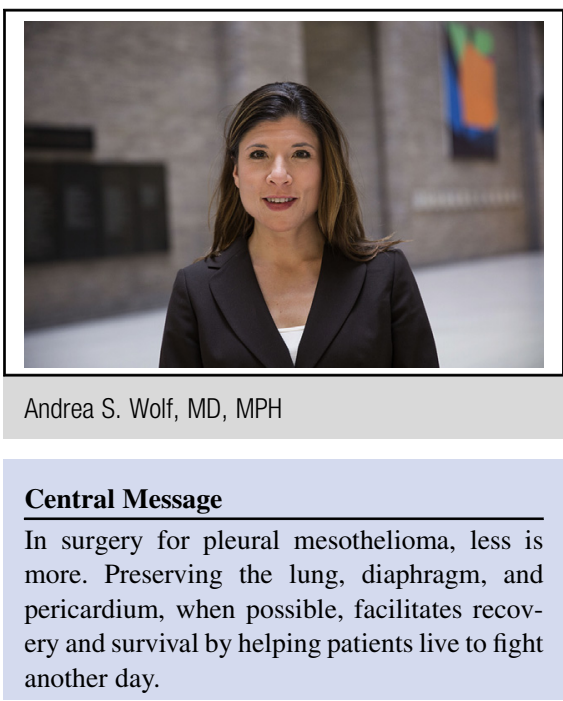

See Article page 1857.

invasiveness in the EPD group. ${ }^{9}$ Batirel and colleagues ${ }^{8}$ demonstrated that leaving small amounts of MPM behind did not reduce long-term survival, and the current study supports this too.

Leaving the pericardium and diaphragm intact may yield superior results by several mechanisms. With a quicker recovery, patients tolerate much-needed adjuvant therapy better and have more reserve to undergo additional treatment when MPM recurs, as data suggest most patients recur. With less extensive surgery, MPM patients live to fight another day. The results of the current study ${ }^{1}$ suggest a possible additional mechanism-leaving the pericardium and diaphragm intact may prevent contamination of unaffected cavities. The update by Baldini and colleagues ${ }^{10}$ on patterns of MPM recurrence after EPP demonstrated $54 \%$ of 169 patients experienced recurrence in the ipsilateral chest or mediastinum and 39\% in the abdomen, whereas only $2 \%$ of patients in the current study ${ }^{1}$ experienced recurrence in the abdomen (and $8 \%$ in the diaphragm).

The study by Ambrogi and colleagues ${ }^{1}$ is too small to draw definitive conclusions, but the key message is the report's biggest strength-in MPM surgery, less is more. There is a point of diminishing returns, and we must measure extent of resection against the goals of preserving function/quality of life, minimizing morbidity, and reducing mortality. Although there is still debate over the actual benefit of surgery in MPM, there is consensus that the patient must live to fight another day. 


\section{References}

1. Ambrogi MC, Bertoglio P, Aprile V, Chella A, Korasidis S, Fontanini G, et al. Diaphragm and lung-preserving surgery with hyperthermic chemotherapy for malignant pleural mesothelioma: a 10 year experience. J Thorac Cardiovasc Surg. 2018;155:1857-66.e2.

2. Richards WG, Zellos L, Bueno R, Jaklitsch MT, Jänne PA, Chirieac LR, et al. Phase I to II study of pleurectomy/decortication and intraoperative intracavitary hyperthermic cisplatin lavage for mesothelioma. J Clin Oncol. 2006;24:1561-7.

3. Wolf AS, Flores RM. Current treatment of mesothelioma: extrapleural pneumonectomy versus pleurectomy/decortication. Thorac Surg Clin. 2016;26:359-75.

4. Sugarbaker DJ, Flores RM, Jaklitsch MT, Richards WG, Strauss GM, Corson JM, et al. Resection margins, extrapleural nodal status, and cell type determine postoperative long-term survival in trimodality therapy of malignant pleural mesothelioma: results in 183 patients. J Thorac Cardiovasc Surg. 1999;117:54-63; discussion: 5.

5. Sugarbaker DJ, Gill RR, Yeap BY, Wolf AS, DaSilva MC, Baldini EH, et al. Hyperthermic intraoperative pleural cisplatin chemotherapy extends interval to recurrence and survival among low-risk patients with malignant pleural mesothelioma undergoing surgical macroscopic complete resection. J Thorac Cardiovasc Surg. 2013;145:955-63.

6. Flores RM, Pass HI, Seshan VE, Dycoco J, Zakowski M, Carbone M, et al. Extrapleural pneumonectomy versus pleurectomy/decortication in the surgical management of malignant pleural mesothelioma: results in 663 patients. $J$ Thorac Cardiovasc Surg. 2008;135:620-6. 626.e1-3.

7. Taioli E, Wolf AS, Flores RM. Meta-analysis of survival after pleurectomy decortication versus extrapleural pneumonectomy in mesothelioma. Ann Thorac Surg. 2015;99:472-80.

8. Batirel HF, Metintas M, Caglar HB, Ak G, Yumuk PF, Yildizeli B, et al. Adoption of pleurectomy and decortication for malignant mesothelioma leads to similar survival as extrapleural pneumonectomy. J Thorac Cardiovasc Surg. 2016;151: 478-84.

9. Marulli G, Breda C, Fontana P, Ratto GB, Leoncini G, Alloisio M, et al. Pleurectomy-decortication in malignant pleural mesothelioma: are different surgical techniques associated with different outcomes? Results from a multicentre study. Eur J Cardiothorac Surg. 2017;52:63-9.

10. Baldini EH, Richards WG, Gill RR, Goodman BM, Winfrey OK, Eisen HM, et al. Updated patterns of failure after multimodality therapy for malignant pleural mesothelioma. J Thorac Cardiovasc Surg. 2015; 149:1374-81. 